\title{
XIII. A direct-reading conductivity-bridge
}

\section{Rollo Appleyard}

To cite this article: Rollo Appleyard (1901) XIII. A direct-reading conductivity-bridge , Philosophical Magazine Series 6, 2:8, 178-179, DOI: 10.1080/14786440109462677

To link to this article: http://dx.doi.org/10.1080/14786440109462677

曲 Published online: 15 Apr 2009.

6 Submit your article to this journal $\pi$

Џll Article views: 2

Q View related articles $₫$ 


\section{[ 178 ]}

XIII. A Direct-reading Conductivity-Bridge.

By Rollo Appleyano*.

W

$\mathrm{HEN}$ it is required to check the conductivity of several tons of copper wire, of the same nominal diameter, the method employed generally resolves itself into making a careful test of the conductivity of the wire of a selected hank, and afterwards balancing a length of this on a slide-bridge against suecessive equal lengths of the remaining hanks of wire of that diameter. If an ordinary slide-bridge is employed, the scale-readings corresponding to the balanceposition of the sliding contact are not directly proportional to the successive conductivities. To arrive at the conductivity a certain amount of arithmetic is necessary. If, however, the slide-bridge is arranged somewhat differently, the readings of the slider can be made to be directly proportional to conductivities.

Let $a$ be the resistance of the selected wire of known conductivity $k_{a}$, and let $b$ be the resistance of any of the remaining wires "hose conductivity $k_{b}$ is to be determined. The third arm of the bridge is a fixed resistance $d$, and the fourth arm is the slide-wire $c$, the resistance of which can be adjusted to balance $d$ by moving the slider.

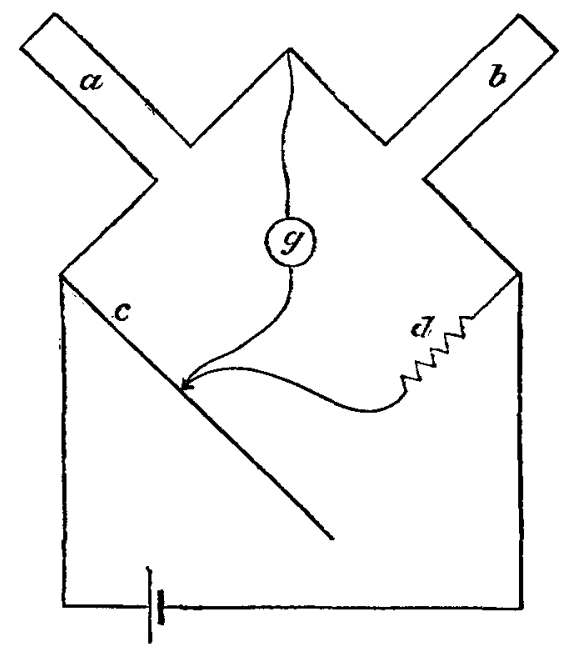

We have therefore,

$$
\frac{d}{b}=\frac{c}{a} \text {. }
$$

* Communicated by the Physical Society : read 8th March, 1901. 
Or, replacing the reciprocals of $b$ and $a$ by their conductivities

$$
\begin{aligned}
d k_{b} & =c k_{a}, \\
k_{b} & =\frac{k_{a}}{d} c .
\end{aligned}
$$

Hence the required conductivitv $k_{b}$ is given in terms of the slide-wire reading, multiplied by a constant $k_{a} / d$.

It is necessary that the contact between $c$ and $d$ should be invariable. The writer finds that the best contact is attained by a device resembling a drill-bow: the slider carries a small brass bow strung with one or more platinum wires, each of which passes once round the slide-wire. Vertical stops fixed to the slider prevent the platinum wires from lagging behind the how as it is moved to right or left.

To graduate the slide-wire scale so that it shall read directly in conductivities, two values of $b$ must be determined by any of the ordinary methods; these wires can then be put into position successively in the conductivity-bridge, and their balance positions marked on the scale. The whole length of the scale can then be divided in corresponding proportion, in equal divisions. The length of the equal divisions into which the scale is divided depends upon the diameter of the wire under test. It is convenient to be able to vary the length of these equal divisions, and also to be able to move the zero to right or left along the slide-wire. This can best be done by a parallel-ruler arrangement, the straight edges being in a vertical plane through the slide-wire. If the top straightedge is then divided into equal parts, plumb-lines from those divisions divide the slide-wire into equal parts of any required length; and the parallel-ruler can be moved, as a whole, along the wire. The angle at which the straight-edge is set depends upon the diameter of the wire under test, the length being constant; the apparatus may therefore be calibraied in diameters as well as in conductivities.

XIV. On the Magnetic Effect of Electrical Convection. By Harold PhNDer*

Historical Review.

$\mathrm{A}^{\mathrm{R}}$ ROM a series of experiments extending over the last four years, M. V. Crémien $\dagger$ has come to the conclusion that a moving electrified body produces no magnetic effect.

* Communicated by Prof. J. S. Ames.

† C. R. t. cxxx. p. 1544 (1900); t. exxxi. p. 578 \& p. $797(1900)$; t. cxxxii. p. $327 \&$ p. 1108 (1901). 